\title{
PREEMPTIVE ANALGESIC EFFECT OF LIDOCAINE IN A CHRONIC NEUROPATHIC PAIN MODEL
}

\author{
Leonardo M. Batista, Igor M. Batista, João P. Almeida, Carlos H. Carvalho, \\ Samuel B. de Castro-Costa, Carlos M. de Castro-Costa
}

\begin{abstract}
Preemptive analgesia inhibits the progression of pain caused by surgical lesions. To analyze the effect of lidocaine on postoperative pain relief, we performed compression of the right sciatic nerve in Wistar rats and observed the differences on behavior between the group that received lidocaine and the group that was not treated with the local anesthetics pre-operatively. Group 1 was not operated (control); group 2 underwent the sciatic nerve ligature without lidocaine; group 3, underwent surgery with previous local infiltration of lidocaine. Group 2 showed significantly longer scratching times with a peak on day 14 post-operative $(p=0.0005)$ and reduction in the latency to both noxious $(p=0.003)$ and non-noxious $(p=0.004)$ thermal stimulus. Group 3 presented significantly shorter scratching times $(p=0.004)$ and longer latency times when compared to Group 2. Preemptive use of lidocaine $2 \%$ can potentially reduce the postoperative neuropathic pain associated with sciatic nerve compression.
\end{abstract}

KEY WORDS: pain, postoperative, sciatic neuropathy, analgesia, lidocaine, experimental animal models.

\begin{abstract}
Efeito analgésico preemptivo da lidocaína em modelo de dor crônica neuropática
Resumo - A analgesia preemptiva inibe a progressão da dor causada por lesão cirúrgica. Para analisar o efeito da lidocaína na diminuição da dor pós-operatória, submetemos ratos Wistar a compressão cirúrgica do nervo ciático e observamos diferenças em alguns padrões de comportamento entre o grupo tratado com lidocaína pré-operatória e o grupo não-tratado com o anestésico local. 0 grupo 1 não foi operado (controle); o grupo 2, submetido a ligadura do nervo ciático sem lidocaína, apresentou significativo aumento do tempo de coçarse com um pico no $14^{\circ}$ pós-operatório $(\mathrm{p}=0.0005)$ e redução na latência para os estímulos térmicos nocivo $(p=0.003$ ) e não-nocivo ( $p=0.004)$; o grupo 3 , operado com a droga preemptiva, demonstrou significativo decréscimo no tempo de coçar-se ( $\mathrm{p}=0.004)$ e maiores tempos de latência quando comparados aos do grupo 2 . O uso preemptivo da lidocaína $2 \%$ pode, potencialmente, reduzir a dor neuropática pós-operatória associada à compressão do nervo ciático.
\end{abstract}

PALAVRAS-CHAVE: dor pós-operatória, neuropatia ciática, analgesia, lidocaína, modelos animais.

Neuropathic pain is characterized by a dull or burning sensation in the setting of hyperalgesia and allodynia and is often represented as a chronic pain ${ }^{1,2}$. Chronic pain usually cannot be controlled by regular treatments. It is well known for its devastating impact in the emotional and cognitive behaviour ${ }^{3}$ and follows the acute postoperative pain in $10-50 \%$ of patients after regular surgeries ${ }^{4}$.
This can be explained by the increased pain responsiveness and neural sensitization developed after the surgical lesion leading to an exaggerated postoperative pain, allodynia and persistent pain, which can be clinically associated with slow recovery, movement restriction, pulmonary embolism and higher blood pressure ${ }^{5,6}$.

Preemptive analgesia may be used before the painful

Laboratory of Neurophysiology and Experimental Neurology, Department of Physiology and Pharmacology, School of Medicine, Federal University of Ceará, Fortaleza CE, Brazil.

This study was partially funded by CNPq - National Counsel of Technological and Scientific Development, Brazil. The facilities used in this project were property of the Laboratory of Neurophysiology and Experimental Neurology, Department of Physiology and Pharmacology, School of Medicine, Federal University of Ceará, Fortaleza CE, Brazil.

Received 23 March 2009, received in final form 28 July 2009. Accepted 10 September 2009.

Dr. Leonardo de Moura Batista - J. Philip Kistler Stroke Research Center / Department of Neurology / Massachusetts General Hospital - 175 Cambridge Street, Suite 300 - Boston MA, 02114, USA. E-mail: Ibatista@nmr.mgh.harvard.edu 
stimulus in an attempt to achieve inhibition or at least reduction of pain intensity after surgical procedures. It works by preventing central sensitization, which is responsible for the secondary development of pain ${ }^{7}$. The animal model of Chronic Constriction Injury ${ }^{8}$ has been used to reproduce the characteristics of the human neuropathic pain secondary to injury, evidenced by an overreaction to the thermal stimuli, excessive limb movement and asymmetric thermal sensitivity in the extremities. Physiologically, aberrant action potentials known as ectopic discharges are conducted via activation of sodium channels along the injured nerve' ${ }^{9}$. Therefore local anesthetics like lidocaine, blocking sodium channels, could suppress ectopic discharges ${ }^{10}$. Two approaches have been described to assess the preemptive analgesic effect: the PRE vs. NO treatment design, where the study will compare preoperative treatment and nontreatment groups; and the PRE vs. POST, which aims to prove that the pre-treatment is more effective than the same drug given at the end of the surgery" ${ }^{1}$. Although preemptive analgesia does not consist in a novel management anymore, its clinical application is still not consensual, and there is not a definition of the most reliable experimental model to test its efficacy ${ }^{7,11,12}$.

The aims of this study are: to assess the feasibility of the Chronic Constriction Injury model in a PRE vs. NO treatment design; to test the efficacy of lidocaine $2 \%$ as a preemptive drug in this combined model; to identify when its effect is more evident within the postoperative observation period.

\section{METHOD}

Animals

All the experiments described in this study were conducted according to the guidelines of the International Association for Study of Pain (IASP) ${ }^{13}$, with the use of a restricted number of animals, avoidance of definitive incapacities and relief of the symptoms caused by the experiments as much as possible. The study was approved by the Animal Ethics Committee of the Federal University of Ceará. Eighteen Wistar rats, weighing about 300g were distributed into 3 different groups consisting of 6 animals each. All rats were kept in an approved laboratory with a 12-hour day $/ 12$-hour night cycle. The animals were fed mouse chow and water ad libitum. The animals in group 1 did not undergo any surgical procedure; the group 2 comprised animals that were submitted to common sciatic nerve constrictive ligature with no preoperative lidocaine treatment, and the rats in group 3 underwent the surgical procedure, receiving lidocaine perioperatively, just before the sciatic constriction.

\section{Common sciatic nerve ligature surgery}

Under anesthesia (phenobarbital sodium $50 \mathrm{mg} / \mathrm{kg}$ intraperitoneal) and aseptic technique, the right sciatic nerve was exposed at the high-thigh level. Animals in group 2 received 0.4
$\mathrm{mL}$ of saline solution (placebo) over the sciatic nerve for $10 \mathrm{~min}$ utes before its ligature. In group 3 , the rats had their right sciatic nerves washed in $0.4 \mathrm{~mL}$ of lidocaine $2 \%$ without vasoconstrictors, for 10 minutes before the chronic constriction injury. After that, a surgical injury was performed on the sciatic nerves of both experimental groups 2 and 3 . The dorsum of the nerve was carefully freed from surrounding connective tissues at a site near the trochanter just distal to the point at which the posterior biceps semitendinosus (PBST) nerve branches off the common sciatic nerve. Using honed (no. 5) jewelers forceps, the nerve was fixed in its place by pinching the epineurium on its dorsal aspect, taking care not to press the nerve against underlying structures. A mononylon 4.0 suture was inserted into the nerve with a $3 / g$ curved, reversed-cutting mini-needle and tightly ligated so that the dorsal $1 / 3-1 / 2$ of the nerve thickness was trapped in the ligature. The wound was then closed using silk suture. The procedure was performed according to the technique described by Bennett and $\mathrm{Xie}^{8}$. A sham surgery was performed in the left leg of the animals in the control group (group 1), with exposure of the common sciatic nerve, but no injury to it. After the exposure of the nerve, the wound was closed with the use of silk suture.

\section{Behavioral observation}

The behavior pattern considered as a sign of neuropathic pain in rats was the scratching activity ${ }^{14}$. The scratching times were collected during observation sessions carried for 28 days, beginning on day zero (pre-op) and followed by the postoperative (post-op) days 2, 3, 7, 14, 21 and 28. Each animal was observed for 30 minutes, after 5 minutes of adaptation to the environment of the observational box.

\section{Thermal test}

Response to thermal stimuli was also analyzed. Tests using non-noxious $\left(40^{\circ} \mathrm{C}\right)$ and noxious $\left(46^{\circ} \mathrm{C}\right)$ stimulation were performed involving immersion of the rat's hind paw in a bath until it was observed the withdrawal or struggle ${ }^{15}$. After 15 seconds of exposure (cut-off), the thermal stimulus was removed even if the animal did not experience any of the behaviors mentioned above and the withdrawal latency to the thermal stimuli was determined. The tests were performed on day zero (preoperative day) and on postoperative days $2,3,7,14,21$ and 28.

\section{Statistical analysis}

The analysis of the results was carried out with the use of the software NCSS/PASS (Cintze J. NCSS and PASS. Number Cruncher Statistical Systems, 2001. Kaysville, Utah). In order to evaluate the differences in times of scratching as well as in the latency to noxious and non-noxious stimuli, the differences between the times obtained in the post-op observational day and in the pre-op observation were used. These differences were reported as $\Delta \mathrm{Scr}$ for scratching behavior and $\Delta$ Lat for latency to thermal stimuli. The differences of $\Delta \mathrm{Scrs}$ and $\Delta$ Lats among 
Table. Hind paw withdrawal latency to noxious $\left(46^{\circ} \mathrm{C}\right)$ and to non-noxious $\left(40^{\circ} \mathrm{C}\right)$ thermal stimuli in each group. Medians and interquartile ranges were used.

\begin{tabular}{lccc}
\hline Group & Noxious stimulus $\left(46^{\circ} \mathrm{C}\right)$ & Non-Noxious stimulus $\left(40^{\circ} \mathrm{C}\right)$ & $\mathrm{P}$ \\
\hline 1 (Not-operated control) & $3.5(3-4)$ & $13(12.2-13.8)$ & 0.001 \\
2 (No-preemptive drug) & $1.5(1.2-2.5)$ & $5.5(5-6.5)$ & 0.01 \\
3 (Preemptive drug) & $8(6-8.2)$ & $9.5(7.5-11)$ & 0.109 \\
\hline
\end{tabular}

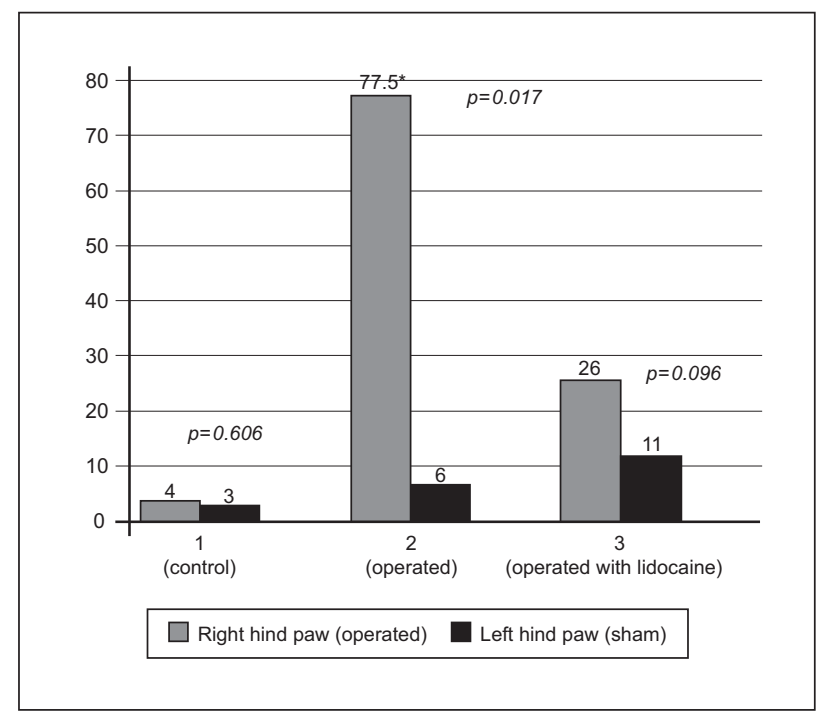

Fig 1. Scratching times in the right and left hind paws. Mirror pain in group 3 suggested by the non-significant difference between the operated and the sham paws. The times are represented in seconds. Medians were used.

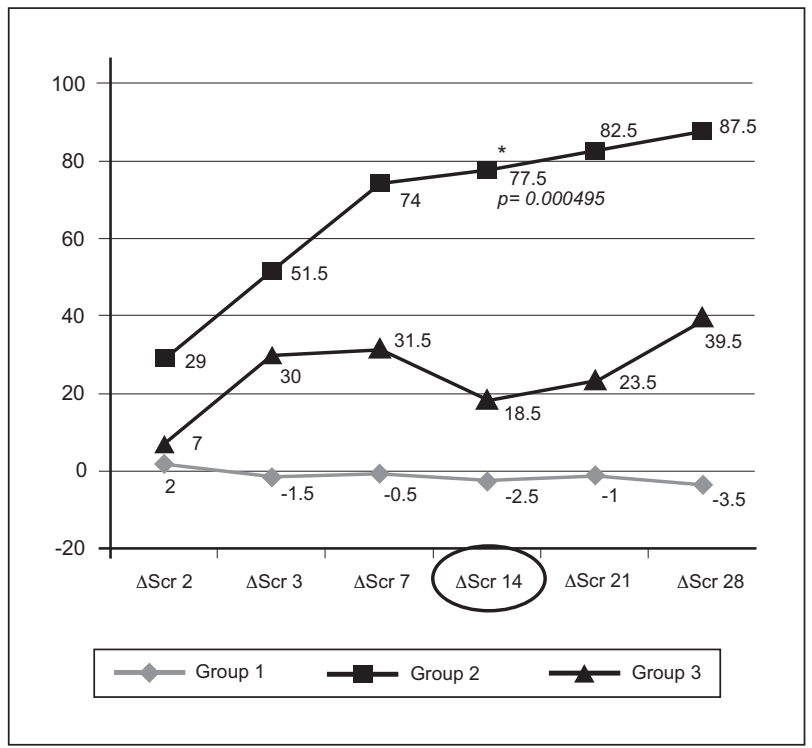

Fig 2. Scratching behavior in the right (operated) hind paws of the three study groups. $\Delta \mathrm{Scr}$ is the difference of the duration of scratching between the given day and the baseline (pre-op) observation. The times are represented in seconds. Medians were used. *post-hoc analyses revealed no significant difference between groups 2 and 3 in $\Delta$ Lat 7, 21 and 28. For all other comparisons, $p<0.04$ was achieved. The maximum difference among the 3 groups was seen in $\Delta$ Lat 14. This was also the greatest difference between groups 1 and 2 and between groups 2 and 3 separately $(p=0.0038$ and $p=0.03$ respectively). the three groups in each day of observation were assessed by a Kruskal-Wallis One-Way ANOVA test. The analysis between two groups was performed with a post-hoc T-test. The significance of the differences the right and left hid paws was assessed by the non-parametric Mann-Whitney $U$ for Difference in Medians test. Values of $p<0.05$ were considered as significant.

\section{RESULTS \\ Group 1}

The animals in group 1 showed median scratching times of 4 and 3 seconds, respectively in the right and left leg, which demonstrate that there is no significant difference in these values (Fig 1). This is a normal pattern since this is an expected behavior in normal animals and does not correspond to pain. Regarding the the thermal tests, the median times of withdrawal latency to noxious stimulus $\left(46^{\circ} \mathrm{C}\right)$ was 3.5 seconds, and to non-noxious stimulus $\left(40^{\circ} \mathrm{C}\right)$ was 13 seconds, evidencing an expected significant difference (Table).

\section{Group 2}

Comparing the scratching times between the right and left side, it was observed that the side where the ligature was performed (right) displayed a significantly longer time (Fig 1). These animals that underwent right common sciatic nerve ligature without preemptive lidocaine presented an increasing curve of scratching values from post-op day 2 to post-op day 28 (Fig 2). They showed significantly longer scratching times in the operated leg than those in group 1, and significantly shorter scratching times than those in group 3 . The peak of these differences in scratching times was seen in post-op day 14 (Fig 2).

Thermal tests presented median times of withdrawal of the hind paw to noxious stimulus of 1.5 seconds, and 5.5 seconds to non-noxious stimulus (Table). This group achieved significantly lower latency times to both noxious and non-noxious stimuli in comparison with the other two groups. The withdrawal latency to the thermal stimuli presented the maximal reduction in the post-op day 14 (Figs 3 and 4).

\section{Group 3}

In group 3 (lidocaine group), the scratching times of both sides progressively increased from the post-op day 2 


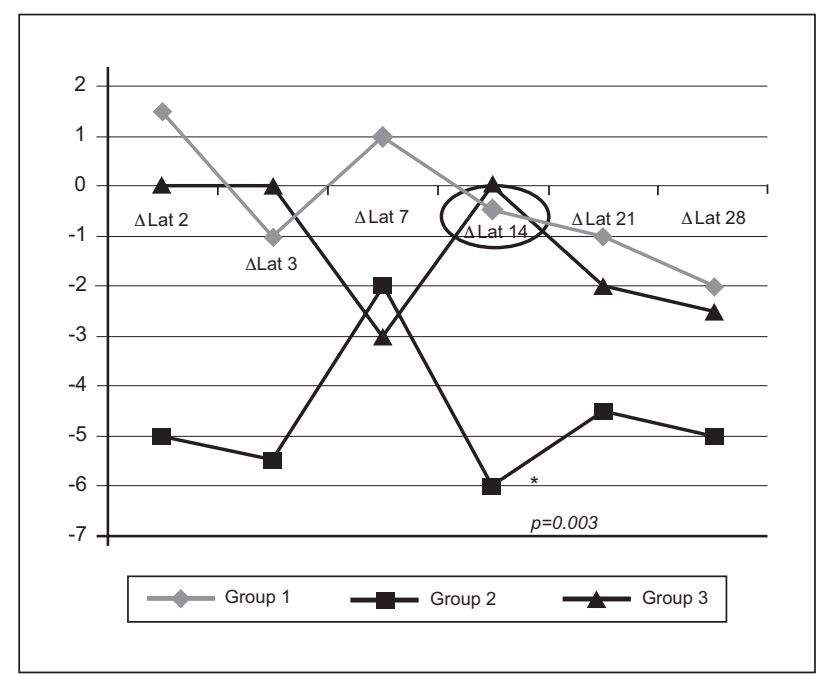

Fig 3. Hind paw withdrawal latency to noxious $\left(46^{\circ} \mathrm{C}\right)$ thermal stimuli among the three study groups. $\Delta$ Lat is the difference of latency between the given day and the baseline (pre-operative) observation. The times are represented in seconds. Medians were used. *- $\Delta$ Lat 14 presented the maximum difference among the three study groups. Post-hoc analyses showed $p<0.037$ for all comparisons (except for $\Delta$ Lat 7 between groups 2 and 3) between Groups 1 and 2 as well as between Groups 2 and 3.

until the post-op day 28 with a marked decrease at day 14 (Fig 2). They showed median scratching times of 26 and 11 seconds, respectively on the right and left sides with no significant difference between the two sides, suggesting a mirror pain pattern (Fig 1). Comparing the scratching times on the right side (operated leg) among the three study groups, the animals in group 3 had significantly shorter scratching times than those in group 2 (without lidocaine), but longer than the time displayed by the control group 1 (Fig 2).

The withdrawal latency was 8 seconds to the noxious stimulus and 9.5 seconds to the non-noxious stimulus, achieving no significant difference (Table 1). However, the hind paw withdrawal latency to the noxious stimulus showed to be significantly longer than in group 2 (Fig 3).

\section{DISCUSSION}

Selecting the proper animal model for the study of neuropathic pain represent one of the most important tools to the further comprehension of mechanisms related to the initiation and progression of pain. Bennett and $\mathrm{Xie}^{8}$ developed one of the most reliable models, the sciatic nerve Chronic Constriction Injury. In an attempt to get rid of the pain, operated rats express spontaneous behaviors manifested as licking, scratching and even tissue-mutilation of the operated hind paw. Since the paw lost its sensory innervations there is no nociceptive input to prevent the animal from expressing autonomy on the paw ${ }^{16}$. It is still not clear whether animals who receive treatment before the trauma show less posttraumatic pain than the

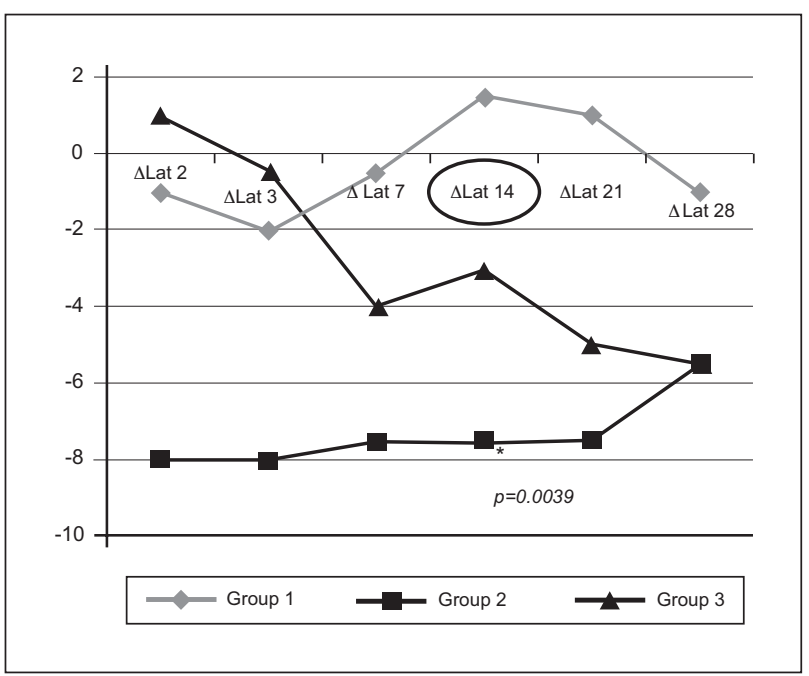

Fig 4. Hind paw withdrawal latency to non-noxious $\left(40^{\circ} \mathrm{C}\right)$ thermal stimuli among the three study groups. $\Delta$ Lat is the difference of latency between the given day and the baseline (pre-operative) observation. The times are represented in seconds. Medians were used *posthoc analyses found no significant difference between groups 2 and 3 in $\Delta$ Lat 7, 21 and 28. For all other comparisons, $p<0.04$ was achieved. The maximum differences between groups 1 and 2 and between groups 2 and 3 were seen in $\Delta$ Lat 14 ( $p=0.0038$ and $p=0.03$ respectively).

ones who receive the medication after the lesion, but the present data document that local pretreatment with lidocaine achieves a marked role preventing hyperalgesia and allodynia. The scratching time on the left side, which did not suffer the sciatic lesion, has been shown to be influenced by the lesion on the contralateral limb in group 3 . The phenomenon known as mirror pain could not be prevented by lidocaine in this study (Fig 1). Whether this will be clinically significant, further studies might be needed. However, it has been successfully demonstrated the inhibition of the mirror neuropathic pain in rats with the administration of opioid in the prefrontal ventrolateral orbital cortex ${ }^{17}$. Animals in group 2, submitted to nerve lesion with no preemptive lidocaine administration, showed significantly higher scratching times when compared to the non-operated animals in group 1 as well as when compared to the rats in the preemptive drug group 3 (Fig 2). The reduction of scratching times achieved by the animals in group 3 demonstrates a potential advantage of the drug as a preemptive analgesic in the study model. Interestingly, the analgesia response in rats pretreated with lidocaine demonstrated a peak on postoperative day 14 , which was also observed in the thermal tests (Figs 3 and 4), suggesting a long-lasting preemptive effect. Another possibility could be that the rats would be presenting some sort of centrally-mediated sensory decline (i.e. hypoesthesia and hypoalgesia) due to the previous lesion. It is known that noxious stimuli may significantly alter somatosensory perception of healthy subjects and chronic pain patients ${ }^{18}$. 
The withdrawal latency to noxious stimulus in group 2 was significantly shorter than those presented on both groups 1 and 3 (Fig 3), suggesting that the latency described for the group 2 was probably secondary to the development of hyperalgesia. On the other hand, the longer withdrawal latency to noxious stimulus revealed in the group pretreated with lidocaine might have resulted from the development of hypoalgesia secondary to the nerve lesion or to the block of the afferent pathways of pain mediated by the drug. During the post-operative day 14 , the latency to noxious stimulus in the lidocaine- treated group was even higher than in the control group (Fig 3).

The lesion of the sciatic nerve was associated with a shorter latency to non-noxious stimulus, as observed in groups 2 and 3 (Fig 4). The change in the response time is possibly due to the development of allodynia in the operated groups. The achievement of hyperalgesia and allodynia suggest that the Chronic Constriction Injury model was successfully reproduced here and that is feasible in combination to the PRE vs. NO treatment design. The group that received pretreatment with lidocaine showed longer latency time when compared to animals that did not receive the treatment, demonstrating the capacity of the drug to inhibit the development of allodynia. Such results support the data obtained in from the scratching analysis, demonstrating the potential of lidocaine in blocking the development of postoperative chronic neuropathic pain.

From our data, we conclude that the combination of the Chronic Constriction Injury model and the PRE vs. NO treatment design is feasible and successfully reproduce the main features of the chronic neuropathic pain. We also suggest that the preemptive use of lidocaine $2 \%$ is effective in reducing the levels of postoperative chronic neuropathic pain in Wistar rats, based on the results of thermal tests and scratching times.

ACKNOWLEDGMENTS - We thank Dr. Nilza D. Alves and Dr. Terezinha J. T. Santos for all the support in the reproduction of this experimental model, Dr. Albert Leyva for English reviewing, Dr. Gisele
Silva and Dr. Fabricio Lima for the statistical guidance and Mr. Silvio A. Costa for the accurate word-processing of this manuscript.

\section{REFERENCES}

1. Smith GR, Monson RA, Ray DC. Patients with multiple unexplained symptoms. Arch Intern Med 1986;146:69-72.

2. Merskey H, Bogduk N. Classification of chronic pain: descriptions of chronic pain syndromes and definitions of pain terms. IASP Press 1994; 2:209-214.

3. Leite-Almeida H, Almeida-Torres L, Mesquita AR, et al. The impact of age on emotional and cognitive behaviours triggered by experimental neuropathy in rats. Pain 2009;144:57-65.

4. Kehlet H, Jensen TS, Woolf CJ. Persistent postsurgical pain: risk factors and prevention. Lancet 2006;367:1618-1625.

5. Coderre TJ. The role of excitatory amino acid receptors and intracellular messengers in persistent nociception after tissue injury in rats. Mol Neurobiol 1993;7:229-246.

6. Von Korff M, Dunn KM. Chronic pain reconsidered. Pain 2008;138: 267-276.

7. Seetharaman H, Moseley H, Kumar A, Raju. The effect of preemptive analgesia in postoperative pain relief: a prospective double-blind randomized study. Pain Med 2009;10:49-53.

8. Bennett GJ, Xie YR. A peripheral mononeuropathy in rats produces disorders of pain sensation like those seen in man. Pain 1988;33:87-107.

9. Lindia JA, Kohler MG, Martin WJ, Abbadie C. Relationship between sodium channel $\mathrm{Na}_{\mathrm{v}} 1.3$ expression and neuropathic pain behavior in rats. Pain 2005;117:145-153.

10. Mao J, Chen LL. Systemic lidocaine for neuropathic pain relief. Pain 2000;87:7-17.

11. Kissin I. Preemptive analgesia at the crossroad. Anesth Analg 2005;100: 754-756.

12. Casals-Díaz L, Vivó M, Navarro X. Nociceptive responses and spinal plastic changes of afferent $\mathrm{C}$-fibers in three neuropathic pain models induced by sciatic nerve injury in the rat. Exp Neurol 2009;217:84-95.

13. IASP Committee for Research and Ethical Issues. Ethical standards for investigation of experimental pain in animals. Pain 1983;16:109-110.

14. De Castro-Costa CM, Gybels J, Kupers R, Hees JV. Scratching behavior in arthritic rats: a sign of chronic pain or itch? Pain 1987;29:123-131.

15. Attal N, Jazat F, Kayser V, Guilbaud G. Further evidence for 'pain-related' behaviours in a model of unilateral peripheral mononeuropathy. Pain 1990;41:235-251.

16. Zhang SH, Blech-Hermoni Y, Faravelli L, Seltzer Z. Ralfinamide administered orally before hindpaw neurectomy or postoperatively provided long-lasting suppression of spontaneous neuropathic pain-related behavior in the rat. Pain 2009;139:293-305.

17. Zhao M, Wang JY, Jia H, Tang JS. Roles of different subtypes of opioid receptors in mediating the ventrolateral orbital cortex opioid-induced inhibition of mirror-neuropathic pain in the rat. Neuroscience 2007; 144:1486-1494

18. De Col R, Maihofner C. Centrally mediated sensory decline induced by differential C-fiber stimulation. Pain 2008;138:556-564. 